\section{Evolutionarily Conserved Essential Genes from Arctic Bacteria: A Tool for Vaccination}

Sir,

Due to advancement in various molecular biological techniques, several indispensable evolutionarily conserved essential genes (genes that are necessary for viability of the living organisms) have been identified over the past decades among various groups of bacteria..$^{[1-3]}$ Moreover, the amino acid sequences of some of these essential genes were highly conserved across various classes of bacteria such as thermophiles (heat-loving) and psychrophiles (cold-loving). However, some of the product of essential genes of psychrophiles have been adapted to the cold environments for millions to billions of years ${ }^{[4-6]}$ thus making these bacteria temperature-sensitive (TS), reduced viability at higher temperatures. In accordance with the above mentioned facts, the human body temperature varies depending upon the body parts, temperature of the skin varies between 32 and $36^{\circ} \mathrm{C}$ whereas the body core is about $37-42^{\circ} \mathrm{C} \cdot{ }^{[7,8]}$ Over decades, attempts have been made to develop TS bacterial strains and viral strains, ${ }^{[9-12]}$ yet bacterial strains were not adapted for human vaccination, ${ }^{[13]}$ for example, the TS version of Yersinia pestis ${ }^{[14]}$ and because of their reversion this strain was not further developed. ${ }^{[13]}$ Further, small numbers of TS bacterial strain vaccines (developed by chemical mutagenesis) were developed for veterinary use; but it is uncertain whether the TS nature is primary attenuating phenotype or merely a coincidental phenotype. ${ }^{[13]}$ In the following work, Duplantis and colleagues have successfully transformed mesophilic pathogenic bacteria to a TS bacterial strain using essential genes from psychrophile and provide evidences for a successful vaccination strategy developed using such TS bacterial strain. The highlight, in the following work, is provided by the concept of using temperature adapted essential orthologue genes from psychrophile to develop the TS non-pathogenic version of bacterial strains.

In this study, the authors chose pathogenic mesophile Francisella tularensis subsp. novicida (F. novicida), maximum growth temperature is about $45^{\circ} \mathrm{C}$, as host to transfer essential genes from a psychrophile Colwellia psychrerythraea, maximum growth temperature is about $19^{\circ} \mathrm{C}$. Strains of F. tularensis is highly virulent to mice but also known to cause zoonotic disease in humans. ${ }^{[15]}$ Here, the selection of host and donor species was based on the similar $\mathrm{G}+\mathrm{C}$ contents of these species. ${ }^{[16,17]}$ In order to maximize the chance that the foreign gene is expressed identically to the homolog that it replaced, the authors engineered the foreign psychrophilic gene under the control of a host promoter and expressed it using host machinery [Figure 1]. The rate of mutation that will revert back the TS strain to a temperature-resistant strain was also assessed by the authors on essential gene such as $\operatorname{lig} A_{S p}, \operatorname{lig} A_{C p}, \operatorname{lig} A_{P b \prime}$ bem $C_{C p}, \operatorname{pyr} G_{C p}$ dnaK $K_{C p}, \operatorname{mur} G_{C p}$ dnaK $K_{S p}$ fmt ${ }_{C p}, f t s Z_{C p}, c m k_{C p}$ and $\operatorname{ty} r S_{C{ }^{\circ}}{ }^{[18]}$

To check the TS viability of the TS F. novicida carrying either $\operatorname{lig} A_{C P}, \operatorname{lig} A_{P b}$ or $d n a K_{C p}$ essential genes, the strains were broth cultured at restrictive temperatures. Results showed an identical growth rate to that of wild-type F. novicida Since F. novicida is a facultative intracellular pathogen, the growth rate of TS F. novicida in infected macrophageslike cell line (J774 cell line) was examined to check the TS viability. The results showed a decline in the number of viable TS F. novicida in the $\mathrm{J} 774$ cell line at restrictive temperature, indicating the temperature sensitivity of TS F. novicida carrying either $\operatorname{lig} A_{C p} \operatorname{lig} A_{P b}$ and $d n a K_{C p}$ essential genes. Moreover, TS F. novicida carrying either lig $A_{C p}$ or lig $A_{P b}$ showed a growth rate similar to wild-type F. novicida at permissive temperatures within infected $\mathrm{J} 774$ cells, whereas strain carrying $d n a K_{C D}$ showed a poor growth indicating the gene-specific variability among the TS strains created. ${ }^{[18]}$

To determine the pathogenic effect caused by TS F. novicida on infected cultured J774 cells, the cells were microscopically examined for their viability. It was found that the J774 cell infected with TS F. novicida remained viable on shifting to restrictive temperature when compared to control (J774 cells infected with wild-type F. novicida), indicating the nonpathogenic nature of engineered TS F. novicida strains. ${ }^{[18]}$

In order to test the capacity of TS F. novicida to grow only in cooler body regions and not in warmer body core, rats and mice were infected with the TS F. novicida at the base of tail. It was observed that TS F. novicida with restrictive temperatures at or below $37^{\circ} \mathrm{C}$ were not found in spleen

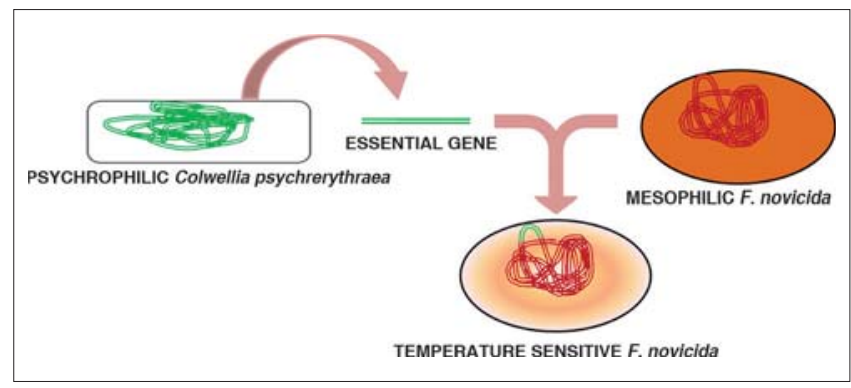

Figure 1: Flowchart representing the transfer of essential gene from a psychrophilic bacterium to a mesophilic bacterium resulting in formation of temperature sensitive mesophilic host bacterium 
whereas F. novicida with restrictive temperature above $37^{\circ} \mathrm{C}$ were detected in spleen (control), indicating the inefficiency of TS F. novicida strains to proliferate at body core organs. Moreover, viable TS F. novicida were found at the site of infection even after 3 days of injection, indicating the capacity of TS F. novicida to survive at cool body parts. These results were further validated by injecting the TS F. novicida into the fleshy part of mouse ears. ${ }^{[18]}$

To check whether the persistence of TS F. novicida at cool body parts induce protective immunity, mice were challenged with intranasal infection of wild-type F. novicida after 21 days of vaccination (injection of TS F. novicida carrying either lig $A_{C D}$ lig $A_{P b}$ or $d n a K_{C D}$ ) at the base of the tail. Using organ bacterial burden, morbidity and weight loss as measures of protection, it was found that TS F. novicida protected the host animal against the challenge caused by wild-type F. novicida [Figure 2]. It was also found that strains carrying $d_{n a} K_{C p}$ showed greater dissemination and least protection, indicating the null role of dissemination in immune stimulation. ${ }^{[18]}$

Furthermore the effect of psychrophilic lig $A$ was also examined in another Gram-negative bacterium, Salmonella enterica. It was found that psychrophilic lig $A$ rendered the organism TS, indicating that this methodology can be applied to numerous important pathogens such as Salmonella thyphi, Escherichia coli, Yersinia pestis etc. Moreover, a codon-optimized version of lig $A_{C p}$ (deleting most of the lig $\left.A_{C P}\right)$ also made Mycobacterium smegmatis TS, indicating the functional ability of $\operatorname{lig} A_{C p}$ product in a Gram-positive lineage bacterium. ${ }^{[18]}$

The technology described in this work by the authors holds good not only to make live TS bacterial vaccines (known to be efficacious for protection against diseases that need cell-mediated immunity) but also in development of killed whole-cell or subunit vaccine and in development of TS version of dangerous bacterial pathogens which can be used to study their biochemical and pathological characteristics without physical containments. ${ }^{[18]}$ Eventhough the Mother Nature has provided with hundreds of evolutionary conserved essential genes, careful selection of the essential gene from psychrophilic species is required to prevent the transformation of genetically engineered TS strains back to temperature-resistant strains through mutations. Technology developed by Duplantis et al. provides the way for engineering other pathogenic bacteria, so that they can be used as vaccines. However successful clinical trials, using TS bacterial strain for protection against bacterial pathogens, and experimentation will provide the way for

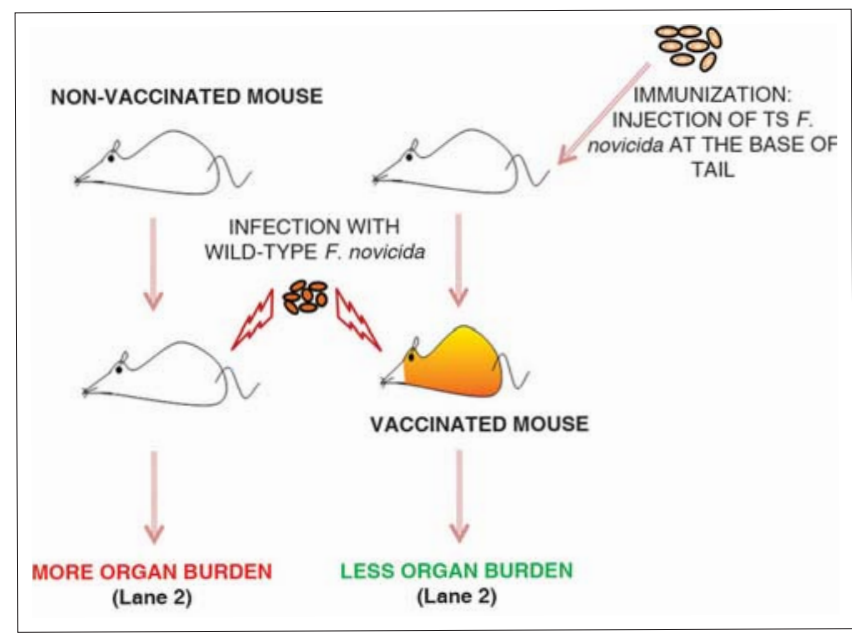

Figure 2: Flowchart indicating the process of vaccination and subsequent protection against wild-type $F$. novicida (lane 2 ) in mouse, whereas showing more organ burden caused in non-vaccinated mouse (lane 1), due to infection with wild-type F. novicida.

the use of this technology for the welfare of humanity.

\section{Shanmugam MM, Parasuraman $\mathbf{S}^{1}$}

Departments of Anatomy and ${ }^{1}$ Pharmacology, Jawaharlal Institute of Postgraduate Medical Education and Research, Puducherry, India

Address for correspondence: Muniesh M. Shanmugam, E-mail: shanmugambms@gmail.com, shanmugambms@gmail.com

\section{REFERENCES}

1. Glass JI, Assad-Garcia N, Alperovich N, Yooseph S, Lewis MR, Maruf M, et al. Essential genes of minimal bacterium. Proc Natl Acad Sci U S A 2006;103:425-30.

2. Sassetti CM, Boyd DH, Rubin EJ. Comprehensive identification of conditionally essential genes in mycobacteria. Proc Natl Acad Sci U S A 2001;98:12712-7.

3. Thanassi JA, Hartman-Neumann SL, Dougherty TJ, Dougherty BA, Pucci MJ. Identification of 113 conserved essential genes using a highthroughput gene disruption system in Streptococcus pneumonia. Nucleic Acids Res 2002;30:3152-62.

4. Marx JC, Blaise V, Collins T, D'Amico S, Delille D, Gratia E, et al. A perspective on cold enzymes: Current knowledge and frequently asked question. Cell Mol Biol (Noisy-le-grand). 2004;50:643-55.

5. Georlette D, Damien B, Blaise V, Depiereux E, Uversky VN, Gerday C, et al. Structural and functional adaptations to extreme temperatures in psychrophilic, mesophilic and thermophilic DNA ligases. J Biol Chem 2003;278:37015-23.

6. Gianese G, Argos P, Pascarella S. Structural adaptation of enzymes to low temperatures. Protein Eng 2001;14:141-8.

7. Benzinger TH. Heat regulation: Homeostasis of central temperature in man. Physiol Rev 1969;49:671-759.

8. Greiner JG, Clegg ME, Walsh ML, White MD. No effect of skin temperature on human ventilation response to hypercapnia during light exercise with a normothermic core temperature. Eur J Appl Physiol 2010;109:109-15. 
9. Chapin M, Dubes GR. Cold-adapted genetic variants of polio viruses. Science 1956;124:586-7.

10. Maassab HF, De Borde DC. Development and characterization of clodadapted viruses for use as live virus vaccines. Vaccine 1985;3:355-69.

11. Belshe RB, Edwards KM, Vesikari T, Black SV, Walker RE, Hultquist M, et al. Live attenuated versus inactivated influenza vaccine in infants and young children. N Engl J Med 2007;356:685-96.

12. Chen Z, Aspelund A, Kemble G, Jin H. Molecular studies of temperaturesensitive replication of the cold-adapted B/Ann Arbor/1/66, the master donor virus for live attenuated influenza FluMist vaccines. Virology 2008;380:354-62.

13. Duplantis BN, Bosio CM, Nano FE. Temperature-sensitive bacterial pathogens generated by the substitution of essential genes from cold-loving bacteria: Potential use as live vaccines. J Mol Med 2011;89:437-44.

14. Munier-Lehmann $\mathrm{H}$, Chenal-Francisque V, Ionescu M, Christova P, Foulon J, Carniel E, et al. Relationship between bacterial virulence and nucleotide metabolism: A mutation in the adenylate kinase gene renders Yersinia Pestis avirulent. J Biochem 2003;373:515-22.

15. Oyston PC. Francisella tularensis: Unreavelling the secrets of an intracellular pathogen. J Med Microbiol 2008;57:921-30.

16. Larsson P, Oyston PC, Chain P, Chu MC, Duffield M, Fuxelius HH, et al. The complete genome sequence of Francisella tularensis, the causative agent of tularemia. Nat Genet 2005;37:153-9.

17. Methe BA, Nelson KE, Deming JW, Momen B, Melamud E, Zhang X, et al. The psychrophilic lifestyle as revealed by the genome sequence of Colvellia psychrerythraea $34 \mathrm{H}$ genomic and proteomic analyses. Proc Natl Acad Sci U S A 2005;102:10913-8.

18. Duplantis BN, Osusky M, Schmerk CL, Ross DR, Bosio CM, Nano FE. Essential genes from Arctic bacteria used to construct stable, temperature-sensitive bacterial vaccines. Proc Natl Acad Sci U S A 2010;107:13456-60.

\begin{tabular}{|l|l|}
\hline \multicolumn{2}{|c|}{ Access this article online } \\
\hline Quick Response Code: & \\
\hline & Website: \\
\hline & www.jyoungpharm.in \\
\cline { 2 - 3 } & DOI: \\
\hline
\end{tabular}

Author Queries???

AQ1: Please check if Dr. or Prof ???

AQ2: $\quad$ Please provide relevant Email ID ??? 